\title{
Treatment of cutaneous leishmaniasis with thermotherapy in Brazil: an efficacy and safety study*
}

\author{
Sheila Viana Castelo Branco Gonçalves ${ }^{1}$
}

Carlos Henrique Nery Costa ${ }^{2}$

DOI: http://dx.doi.org/10.1590/abd1806-4841.20186415

\begin{abstract}
BACKGROUND: Pentavalent antimonials remain as the standard drugs in the treatment of cutaneous leishmaniosis. The high cost, difficult administration, long treatment time, toxicity and increasing morbidity are factors that limit the use of these drugs.

OвJECTIVES: To describe the response to radiofrequency thermotherapy in the treatment of localized cutaneous leishmaniasis in Brazil, and to evaluate its safety and tolerability.

MEtHODs: We conducted a non-comparative open trial with a total of 15 patients confirmed to have cutaneous leishmaniasis on parasitological examination. A single radiofrequency thermotherapy session at $50^{\circ} \mathrm{C}$ for 30 seconds was applied to the lesion and its edges. In patients with more than one lesion, only the largest one was treated initially. If after 30 days there was no evidence of healing, the smaller lesion was also treated with thermotherapy. Clinical cure was defined as visible healing for three months after treatment. The patients were followed-up for six months and there was no follow-up loss.
\end{abstract}

REsults: Of all 23 lesions, only two evolved to complete healing without the need of treatment. Of 21 lesions, 18 (85.7\%) achieved full healing. The main observed side effects were itching, burning sensation, pain and blisters.

StUDY LIMITATIONS: Sample with a small number of patients and short follow-up.

CONCLUSION: Thermotherapy can be considered a therapeutic alternative in localized cutaneous leishmaniasis, especially in cases of single cutaneous lesions and with formal contraindications to conventional treatment with pentavalent antimonials.

Keywords: Hyperthermia, induced; Leishmania; Leishmaniasis, cutaneous; Therapeutics

\section{INTRODUCTION}

Cutaneous leishmaniasis (CL) is an infectious disease caused by protozoa of the genus Leishmania, transmitted to men and other mammals through the bite of phlebotomine sandflies. The disease is endemic in more than 70 countries, with $90 \%$ of cases occurring in Afghanistan, Algeria, Brazil, Pakistan, Peru, Saudi Arabia and Syria. In the New World, it is found from the south of the United States to the north of Argentina. The annual incidence is estimated in 1-1.5 million cases. ${ }^{1,2}$ In Brazil, it is present in all states, with an increased incidence over the last 20 years, with a mean of 25,000 new cases/year and 8 to 18 cases/100,000 inhabitants. The North region contributes with the larger number of cases (around $40 \%$ of the total of registered cases) and has the highest mean coefficients (73.3 cases /100,000 inhabit.), followed by the Mid-West (35.4 cases/100,000 inhabit.) and Northeast (18.8 cases/100,000 inhabit.) regions. ${ }^{3}$ Although the state of Piauí, located in the Northeast of Brazil, is one of the states with the highest number of visceral leishmaniasis, its incidence of CL remains low, occupying the $4^{\text {th }}$ place among the states of the Northeast. In 2014, the state of Piauí notified 85 cases of American tegumentary leishmaniasis, with a coefficient of detection of 4.1 cases per 100,000 inhabitants. ${ }^{4}$

Leishmaniases are among the most neglected diseases due to the limited resources invested in its diagnosis, treatment and control, together with its strong association to poverty and social conflicts. They occur more frequently in economically unfavored areas, without basic sanitation, low educational and income levels. ${ }^{5}$ They represent one of the dermatological conditions that most deserve attention due to their magnitude, by the risk of causing deformities in humans and also by the psychological involvement, that is reflected in the social and economic fields. ${ }^{2}$

In Brazil, the condition is also known as American tegumentary leishmaniasis (ATL), caused basically by three main species: Leishmania (Viannia) braziliensis, Leishmania (Viannia) guyanensis and Leishmania (Leishmania) amazonensis. However, most cases are caused by L. (V.) braziliensis, originating the main clinical form of

\footnotetext{
Received 06 September 2016.

Accepted 19 March 2017.

* Work conducted at Institute for Tropical Diseases Natan Portella, Universidade Federal do Piauí (UFPI), Teresina (PI), Brazil

Financial support: FADEX - Fundação Cultural e de Fomento à Pesquisa, Ensino e Extensão e Inovação.

Conflict of interest: None.

Outpatient Clinic of Dermatology, Hospital Getúlio Vargas (HGV), Teresina (PI), Brazil.

Department of Community Medicine, Universidade Federal do Piauí (UFPI), Teresina (PI), Brazil.
}

MAILING ADDRESS:

Sheila Viana Castelo Branco Gonçalves

E-mail: sheilacastelo@hotmail.com

(C)2018 by Anais Brasileiros de Dermatologia

(c) BY-NC 
ATL, localized CL. Other less common species causing the disease are L. (Viannia) lainsoni, L. (Viannia) naiffi, L. (Viannia) shawi and L. (Viannia) lindenbergi. ${ }^{3,6}$ The vectors are phlebotomine commonly known as sandflies, tatuquiras, birigui, with Lutzomyia flaviscutellata, L. whitmani, L. umbratilis, L. intermedia, L. wellcome e L. migonei being the main species involved in the transmission. ${ }^{7}$

Clinical manifestations of ATL are diverse, depending on the Leishmania species involved and host factors, including their immune response. It is also possible that these factors have a role in the persistence of the parasite. ${ }^{8}$ Clinically, ATL can present basically in 4 forms: localized CL, mucocutaneous leishmaniasis, disseminated CL and diffuse CL. The initial manifestation of the disease is characterized by an erythematous papule or nodule, usually on an exposed area of the skin, that progresses to a well-defined ulcer with rolled edges and coarse granulations in the center, covered by a serous-bloody exudate or not. They are usually found on exposed areas like the face, arms and legs. ${ }^{9}$ The involvement of nasal mucosa, palate, pharynx, larynx and vocal cords can be seen in up to $5 \%$ of patients. Regional lymph node enlargement, with or without lymphangitis, occurs in $12-30 \%$ of cases. ${ }^{10}$

Even though the diagnosis of CL can be made only by clinical-epidemiological criteria, ancillary tests are essential to differentiate the disease from other infectious, inflammatory and neoplastic dermatoses. Diagnosis is confirmed when the parasite is identified on direct examination, culture in specific media, skin histology or polymerase chain reaction (PCR). ${ }^{11}$ Montenegro intradermal test is an indirect method used to aid in the confirmation of the diagnosis. ${ }^{12}$

CL lesions can heal spontaneously, but that would take months to years. When not treated, complications such as disease extension into mucous membranes or disfiguring lesions can occur. This is particularly important in infections with the species belonging to the subgenus L. viannia (L. viannia braziliensis, L. viannia guyanensis and L. viannia panamensis), that have shown a strong tendency to systemic dissemination when compared to other species. ${ }^{13}$

Despite multiple efforts dedicated to the development of new drugs for the treatment of CL, pentavalent antimonials have been used for many decades as the drug of first choice. Commercially available are meglumine antimoniate (Glucantime ${ }^{\circledast}$ ) and sodium stibogluconate (Pentostam $\left.{ }^{\circledR}\right){ }^{14}$ Brazil's Ministry of Health recommends 10 to $20 \mathrm{mg} / \mathrm{kg} /$ day of intravenous or intramuscular Glucantime ${ }^{\circledR}$, during 20 days for the treatment of cutaneous forms. In case there is no complete healing three months after treatment, the regimen should be repeated for 30 days. If there is still lack of response, a second line drug should be used. ${ }^{3}$

One of the greatest problems regarding the use of pentavalent antimonials are their side effects. The main side effects include arthralgia, myalgia, anorexia, nausea, vomiting, postprandial fullness, epigastralgia, heartburn, abdominal pain, pruritus, fever, weakness, headache, dizziness, insomnia, palpitation, edema, hepatitis with increased transaminases and alkaline phosphatase, acute renal failure, pancreatitis and dose-dependent changes on electrocardiogram, such as alteration of the ventricular repolarization with ST inversion, prolongation of the QT interval, ischemic changes and bigeminy, polymorphic and polyfocal. ${ }^{15,16}$ Fatal arrhythmias are rare, with only a few cases of sudden death, likely related to ventricular arrhythmias. ${ }^{17}$ These reactions are more pronounced in the elderly and the drug should be used with caution in those older than 50 years old. ${ }^{18}$

Another disadvantage of this class of drugs is that they are contraindicated during pregnancy, lactation, individuals with hypersensitivity to the drug and patients with severe, chronic conditions (heart, liver, kidney diseases). ${ }^{14}$ The success rate with the described regimen is very variable in the literature, ranging from 60 to $90 \%$, according to different authors and in studies conducted in different areas and services. ${ }^{16,19}$ It is worth highlighting that, even with the appropriate antimonial treatment, recurrences of mucosal involvement can occur in $2 \%$, of treated cases and around $10 \%$ in untreated cases. ${ }^{10}$ Antimonial resistance by some Old World Leishmania species is another increasing problem, even though this has not been observed in Brazil. ${ }^{20}$ The prolonged course of treatment and the fact that the applications are multiple and painful, lead to the discontinuation of the treatment by the patient, possibly making the poor adherence one of the main causes for the appearance of strains resistant to the standard treatment.

The use of second line medications such as amphotericin B and pentamidine is indicated in cases of resistance or when meglumine antimoniate is unavailable. ${ }^{3}$ However, they have as limitations the high cost and the need of higher complexity services for the administration, as well as frequent and severe side effects. ${ }^{21,22}$

Historically, application of local heat has been used to treat CL lesions. In rural communities in South America and Africa, the empiric use of caustic materials such as silver nitrate, gunpowder, brown sugar, oil, battery solution or cauterization of lesions with a drop of candle wax or heated metal objects, such as forks and spoons is very common. ${ }^{23-25}$ In a study performed in rural areas of Ecuador, multiple alternative treatment methods were identified such as the application of caustics, petroleum products, heavy metals, veterinary products and preparations of plants and medicinal herbs. Many of these treatments were described by research participants as "hot "or "strong", since they caused intense burning and pain. According to them, heating the lesions increased their chances of cure. ${ }^{26}$

Laboratory studies demonstrated that Leishmania species that cause cutaneous disease cannot multiply inside macrophages in temperatures above $39^{\circ} \mathrm{C}$, and thermosensitivity is especially high for L. braziliensis and L. mexicana. These studies suggest that there is a growth and survival phase of these parasites that is sensitive to heat. ${ }^{27,28}$ These observations fostered the use of thermotherapy with hot baths, infrared light, direct electric stimulation, laser and photodynamic therapy for the treatment of CL lesions. ${ }^{29-33}$

Radiofrequency therapy has distinct advantages over other local methods of treatment. The heat produced by the radiofrequency waves penetrates uniformly to a depth of $4 \mathrm{~mm}$, in a way that the upper dermis, where are the amastigote forms of Leishmania, can be heated to high temperatures without damaging the surrounding skin. Besides, radiofrequency waves can be made by portable devices. The first study of its efficacy was performed in Guatemala with 66 randomized CL patients by L. braziliensis and L. mexicana and demonstrated a rate of cure of $73 \%$, the same as patients treated with systemic pentavalent antimonial. ${ }^{34}$ However, in two randomized studies that also compared thermotherapy with systemic 
pentavalent antimonial performed in Colombia, the cure rates were lower, around $60 \%$ but still with the advantage of less costs and less side effects with radiofrequency thermotherapy. One of them randomized 292 patients with the diagnosis of CL by L. panamensis and L. braziliensis into two groups, the thermotherapy group and the systemic antimonial. In this study there was no statistically significant difference regarding the species in the response of the treatment used. The other randomized 130 with CL caused especially by $L$. guyanensis to receive conventional treatment and thermotherapy. ${ }^{35,36}$

Multiple randomized clinical trials compared thermotherapy to other therapeutic alternatives. A controlled randomized study performed in Afghanistan to treat CL by L. tropica with 401 patients, demonstrated $69.4 \%$ efficacy when compared to intralesional antimonial $(75.3 \%)$ and intramuscular antimonial (44.8\%). ${ }^{37}$ Later, a controlled randomized trial performed in Iran with 117 patients showed superiority of radiofrequency thermotherapy (80.7\%) when compared to intralesional antimonial (55.3\%). ${ }^{38}$ Another randomized controlled study treated CL by L. major in 54 American soldiers returning from Iran and Kuwait and achieved similar cure between thermotherapy (48\%) and intravenous pentavalent antimonial (54\%) but with much less side effects with thermotherapy ${ }^{39} \mathrm{~A}$ recent study performed in India with 100 patients randomized into two groups showed an elevated efficacy of both the radiofrequency thermotherapy and the intralesional antimonial after 12 weeks follow-up..$^{40}$ The efficacy and safety of miltefosine was compared to thermotherapy in a randomized controlled trial with 294 CL patients by L. panamensis and L. braziliensis performed in Colombia. There was no statistically significant difference between both treatments, which demonstrated a cure rate around $70 \%$. There was also no statistically significant difference in the response to treatment regarding the causative species of the disease. However, the number of side effects reported with miltefosine was higher. ${ }^{41}$

In Brazil, a study performed in Bahia compared the systemic inflammatory response through the dosage of inflammatory cytokines after radiofrequency thermotherapy and after conventional treatment with pentavalent antimonial and demonstrated that, in both, there was an elevation in the inflammatory cytokines, with no statistically significant difference. However, it is not known if this change in the inflammatory response is a direct result of thermotherapy and the systemic medication or if it results from the healing process triggered by the treatments performed. It was also noted that in a patient with only one of two lesions treated with radiofrequency thermotherapy, the untreated lesion progressed to healing. ${ }^{42}$

This healing effect of the therapy in distant untreated lesions can be explained by systemic inflammatory changes that occur. After application of the heat therapy, there is a significant decline in the circulating T-cells and NK-like T-cells (natural killer-like), followed by an expansion of the NK cells (natural killer). A decline in the cellular proliferation of antigen-specific $\mathrm{T} \mathrm{CD} 4^{+}$is also seen, as well as a depletion in the $\mathrm{T} \mathrm{CD8}{ }^{+}$cells. Besides, the healing period was characterized by a decrease in the circulating regulatory T-cells, reduction in the production of IFN- $\gamma$ and contraction in $\mathrm{T}$ helper $\mathrm{CD}^{+}$polyfunctional cells. ${ }^{43}$

Although the studies conducted exclude immunosuppressed patients, there is a case report of an HIV-positive patient with CL who did not respond well to the treatment with intralesional antimonial and was then treated with one session of radiofrequency thermotherapy with a good response, demonstrating that, in immunosuppression cases or in those with contraindications to the conventional treatment, thermotherapy can be a satisfactory alternative. $^{44}$

To date, there are no approved vaccines against leishmaniasis and the drugs used for its treatment are extremely toxic, expensive and difficult to use. Therapeutic options for this disease remain very restricted. Moreover, there are evidences in the Old World of parasite resistance to the drugs commonly used, such as pentavalent antimonials. The search for new treatment options with few side effects, low toxicity, good tolerability, ease of use, with a reduced treatment time and low cost is necessary to spare individuals of the inconveniences of traditional therapies. The objective of this study is to describe the response to the treatment of CL with radiofrequency thermotherapy and evaluate safety and tolerability of thermotherapy for the treatment of CL.

\section{METHODS}

A non-comparative open clinical trial was performed with 15 patients seen at the Hospital de Doenças Tropicais Natan Portella, a reference for infectious diseases in the state of Piauí, in some cities of the state of Maranhão and the Laboratório de Pesquisas em Leishmanioses (Lableish) in Teresina, Piauí, Brazil, from April to September 2015. All patients clinically suspicious for CL underwent ancillary tests to confirm the clinical diagnosis of CL. Montenegro skin test was performed on the medial surface of the forearm and the reaction measured 48 hours later. A biopsy of the lesion was also performed and the sample was used for histology, direct examination, culture and conventional PCR with the primers 150/152. When the lesions were secondarily infected, they were previously treated with cephalexin. All patients were tested for the human immunodeficiency virus and had general blood biochemistry.

Patients with the clinical-epidemiological diagnosis of $\mathrm{CL}$, with a positive Montenegro test associated to at least one of the following ancillary tests were included in the study: demonstration of the parasite by direct observation in the lesion or with culture (medium Neal, Novy and Nicolle/NNN - modified agar blood), or by suggestive histology or by conventional PCR.

Exclusion criteria were the presence of lesions on the oral or nasal mucosae, presence of more than 10 cutaneous lesions, CL lesions within $2 \mathrm{~cm}$ of the orbit, lesions on the nose, lips, eyes, urogenital or anal opening or adjacent to these sites and immunosuppressed patients.

After receiving detailed instructions about the study and the procedures performed, all patients or their guardians signed the consent form.

After disinfection of the lesions with iodine and local anesthesia with lidocaine $2 \%$ without vasoconstrictor, one session of treatment was performed using the portable radiofrequency device ThermoMed Model 1.8 (Thermosurgery Technologies, Inc., Phoenix, AZ, USA), according to the manufacturer's instructions. Before the treatment, the tip of the device was applied to the border of the lesion, pointing to the center, heating it to a temperature of $50^{\circ} \mathrm{C}$ 
for 30 seconds and then the tip was moved to an adjacent portion until the lesion was completely covered. The size of the lesion was the determinant of the number of applications and the time spent in the session.

After selecting the desired temperature for the treatment $\left(50^{\circ} \mathrm{C}\right)$, the device regulates the energy and maintains the selected temperature. Through a digital screen, it is possible to detect the temperature reached in the skin. The device emits a beep every two seconds and a louder sound after the selected time is finished, indicating that the treatment planned has come to an end, without the need of looking at the device. The application causes local erythe$\mathrm{ma}$, therefore it is possible to identify which areas of the lesion were already treated and which were not. The device is light and uses rechargeable batteries, making it possible its use in rural areas or those with no electricity. It operated when the electrodes are applied on the skin, generating heat when the radiofrequency waves pass between two electrodes, reaching an area of about $3 \times 4 \mathrm{~mm}$.

After the treatment, the patients were advised to cover the lesion with gauze and apply fusidic acid cream for seven days to avoid secondary infection. Patients were reviewed at 15 days, 30 days, 90 days, 180 days and 360 days. However, they were instructed to return in case of any complications. Photographs were taken before the treatment and in every follow-up.

When the patient had more than one lesion, the treatment was initially performed only in the larger one. If, after 30 days of the treatment, the remaining lesions did not show any signs of healing, radiofrequency thermotherapy was also performed on them.

Clinical cure was defined as complete epithelialization, total regression of the edema and erythema and visible scarring for three months after the treatment. Definitive cure was considered when there was no recurrence six months after the treatment. The total patient follow-up was of 12 months.

The patients that did not respond to this treatment were treated with meglumine antimoniate with the dose of $20 \mathrm{mg} / \mathrm{Sb}^{+5} /$ $\mathrm{kg} /$ day for 20 days, according to the recommendation of the Ministry of Health, Brazil.

Data collected were inserted into the program Microsoft Windows Excel $2010^{\circledR}$ and were processed and analyzed with the statistical program Stata/SE ${ }^{\circledR} 14.1$ for Windows (College Station, Texas, USA), with which an analysis of frequency distribution and calculation of the $95 \%$ confidence interval were performed. The program Microsoft Windows Excel $2010^{\circledR}$ was also used for the tables and graphs.

\section{RESULTS}

A total of 15 patients participate in the study from April to September 2015. All patients had the diagnosis confirmed by at least one ancillary test performed. Demographic and clinical features of the patients are shown in table 1.

The mean age of the patients was 43 years, with a minimum of 16 years and maximum of 79 years, being $60 \%$ of patients male. More than half of the patients had only one lesion, and only one patient had three lesions. None of the patients had a previous history of leishmaniasis, however, five patients reported that some family member already had the disease. Secondary infection was seen before the treatment in five patients and was adequately treated with oral cephalexin before the treatment. The parasitological diagnosis was confirmed in $60 \%$ of patients with the presence of amastigotes. The remaining patients had a histology suggestive of CL. Among the changes found, the most common were chronic granulomatous dermatitis with pseudoepitheliomatous hyperplasia in the epidermis and lymphoplasmacytic inflammatory infiltrate. Montenegro test was performed in all patients, and the two-digit mean of the test result was of $10.7 \mathrm{~mm}$. Culture was positive for Leishmania sp in only two $(25 \%)$ out of eight patients in which this exam was performed. All patients included in the study had a conventional PCR positive to Leishmania sp.

A total of 23 lesions was evaluated and of those, most were ulcers $(56.52 \%)$, followed by plaques $(21.74 \%)$, papules $(13.04 \%)$ and nodules $(8.7 \%)$. Regarding the site of the lesions, the majority was located on the lower limbs $(60.87 \%), 30.43 \%$, on the upper limbs and $8.7 \%$, on the head. The mean duration of the lesions reported by the patients was around three months (Table 2).

All patients returned for follow-up and there was no loss to follow-up. Complete cure in three months after the treatment was seen in 13 patients ( $86.67 \%$ CI $95 \% 54.63 \%$ to $97.23 \%$ ) (Table 3). The mean cure time of the 13 patients considered to be cured was of two months. None of the patients who had complete healing of the lesions had recurrence of the lesions in 12 months of follow-up.

Of the seven patients with more than one lesion, only two had healing of the untreated lesions (Figure 1). Five needed radiofrequency thermotherapy for the remaining lesions and not only on the larger lesion. This happened because, after 30 days of the initial treatment, the adjacent lesions did not show signs of progression to healing and some of them even increased in size.

One patient did not achieve cure after three months of follow-up and refused systemic therapy with meglumine antimoniate but evolved with a good response and complete healing of her two lesions three months after another session of radiofrequency thermotherapy (Figure 2). The other patient considered as a therapeutic failure had a $75 \%$ reduction in his ulcer but did not show a complete reepithelialization of the skin to considered completely cured. This patient was treated with meglumine antimoniate.

Of the total of 23 lesions, only 15 were treated initially (one from each patient). After 30 days, the lesions were reassessed and only two $(25 \%)$ of the eight untreated lesions did not progress to cure without the need of thermotherapy. Thus, of the 21 lesions treated, 18 progressed to cure after the treatment (85.7\% CI 95\% 63.7\% to $97.0 \%$ ) (Table 4). Two were excluded from the analysis because they were not treated.

The main side effects reported by the patients were pain (33.3\%), itch (16.7\%) and burning sensation (5.6\%). Only one of the patients developed blisters on the application site. Seven patients (38.9\%) denied any side effect. No secondary infection was seen after the treatment.

The area of reepithelialization of 13 lesions (56.5\%) had an excellent aspect, acquiring almost the same color of the initial skin (Figure 3). Healing with hyperpigmentation was seen in $34.8 \%$ of the lesions, and only one patient who had two lesions healed with hypopigmentation. 


\begin{tabular}{|c|c|c|}
\hline Age (years) & Mean \pm SD & $43.47 \pm 20.97$ \\
\hline \multirow[t]{2}{*}{ Sex } & Male & $9(60.00 \%)$ \\
\hline & Female & $6(40.00 \%)$ \\
\hline \multirow[t]{3}{*}{ No. of lesions } & One lesion & $8(53.33 \%)$ \\
\hline & Two lesions & $6(40.00 \%)$ \\
\hline & Three lesions & $1(6.67 \%)$ \\
\hline \multirow[t]{2}{*}{ Family history of leishmaniasis } & yes & $5(33.33 \%)$ \\
\hline & no & $10(66.67 \%)$ \\
\hline \multirow[t]{2}{*}{ Secondary infection } & yes & $5(33.33 \%)$ \\
\hline & no & $10(66.67 \%)$ \\
\hline \multirow[t]{2}{*}{ Lymph node enlargement } & yes & $1(6.67 \%)$ \\
\hline & no & $14(93.33 \%)$ \\
\hline \multirow[t]{2}{*}{ Amastigotes on histology } & yes & $9(60.00 \%)$ \\
\hline & no & $6(40.00 \%)$ \\
\hline Montenegro test (mm) & Mean \pm SD & $10.70 \pm 1.99$ \\
\hline
\end{tabular}

$\mathrm{SD}=$ standard deviation; $\mathrm{CI}(95 \%)=95 \%$ confidence interval for the mean

\begin{tabular}{lllll}
\multicolumn{5}{c}{ TABLE 2: Features of the lesions $(\mathbf{n}=23)$} \\
\hline & Description & N & $\%$ & Median \pm SD \\
\cline { 2 - 5 } Type of lesion & Papule & 3 & $13.04 \%$ & \\
& Plaque & 5 & $21.74 \%$ & \\
& Nodule & 2 & $8.7 \%$ & \\
& Ulcer & 13 & $56.52 \%$ & \\
& UL & 7 & $30.43 \%$ & \\
& LL & 14 & $60.87 \%$ & \\
$\begin{array}{l}\text { Site of the } \\
\text { lesions }\end{array}$ & Head & 2 & $8.70 \%$ & \\
$\begin{array}{l}\text { Duration of } \\
\text { the lesions } \\
\text { (months) }\end{array}$ & & & & $300 \pm 365.8$ \\
$\begin{array}{l}\text { Lesional area } \\
\text { (mm }{ }^{2} \text { ) }\end{array}$ & & & & \\
\hline
\end{tabular}

$\mathrm{SD}=$ standard deviation; $\mathrm{UL}=$ upper limbs; $\mathrm{LL}=$ lower limbs.

\section{TABLE 3: Cure rates of the patients treated with thermotherapy}

\begin{tabular}{llll}
\hline $\begin{array}{l}\text { Number of } \\
\text { sessions }\end{array}$ & $\begin{array}{l}\text { No. of } \\
\text { patients } \\
\text { treated }\end{array}$ & $\begin{array}{l}\text { No. (\%) of } \\
\text { patients } \\
\text { cured }\end{array}$ & CI (95\%) \\
\hline $\begin{array}{l}\text { One sessions } \\
\begin{array}{l}\text { Two sessions (one in } \\
\text { each lesion) }\end{array}\end{array}$ & 10 & $9(90.0 \%)$ & \\
$\begin{array}{l}\text { Three sessions (one in } \\
\text { each lesion) }\end{array}$ & 1 & $3(75.0 \%)$ & \\
Total & 15 & $1(100.0 \%)$ & \\
& & $\mathbf{1 3 ( 8 6 . 7 \% )}$ & $\begin{array}{l}\mathbf{5 4 . 6 \%} \text { to } \\
\mathbf{9 7 . 2} \%\end{array}$ \\
\hline
\end{tabular}

CI $(95 \%)=95 \%$ confidence interval for the mean.

\section{DISCUSSION}

The results of this study show that radiofrequency thermotherapy can be considered as an alternative therapy to the conventional treatment of localized CL. The sample was restricted to 15 patients because of the short interval available for data collection and the execution of the study, associated to the small number of notified cases in this period in the state of Piauí. Despite all that, we consider that this sample has demographic and clinical features that are representative of the population usually affected by this disease.

Radiofrequency thermotherapy had a cure rate of $87 \%$, one of the highest when compared to other previous studies, even though with a broad confidence interval (CI 95\% 54.6\% to 97.2\%). A meta-analysis of controlled clinical trials with cutaneous infection by different species evaluated the efficacy of thermotherapy and found a mean efficacy of $73.2 \%$, inferior to the one in this study. ${ }^{45}$ The highest cure rates ever described with this treatment modality were in India (98\%), in a study conducted to compare the efficacy of thermotherapy and intralesional antimonial (94\%) in patients with $L$. tropica lesions. ${ }^{40}$ One study performed at a military hospital in Washington, with soldier that acquired the disease by L.major in Iraq or Kuwait, showed one of the lower cure rates (48\%) among the studies published..$^{39}$

It is possible that factors such as the host immunological response and their nutritional status, as well as differences between the species causative of the disease are responsible for the discrepancy between the cure rates found in the studies. Although in our study the Leishmania species causative of the disease was not identified, it is likely that the lesions have been caused by L. braziliensis in the majority of patients. ${ }^{3}$ A study performed previously in Guatemala with 66 patients to assess the efficacy of thermotherapy demonstrated an efficacy of $73 \%$ in patients with CL by L. braziliensis and L. mexicana, the same as patients treated with systemic pentavalent antimonial. ${ }^{34}$ In other two randomized studies that also compared thermotherapy with systemic pentavalent antimonial performed in Colombia, the cure rate was lower, around $60 \%$. In these studies, the species responsible for the infection were $L$. panamensis, L. braziliensis and $L$. guyanensis. ${ }^{35,36}$ If we compare the results of these studies with other

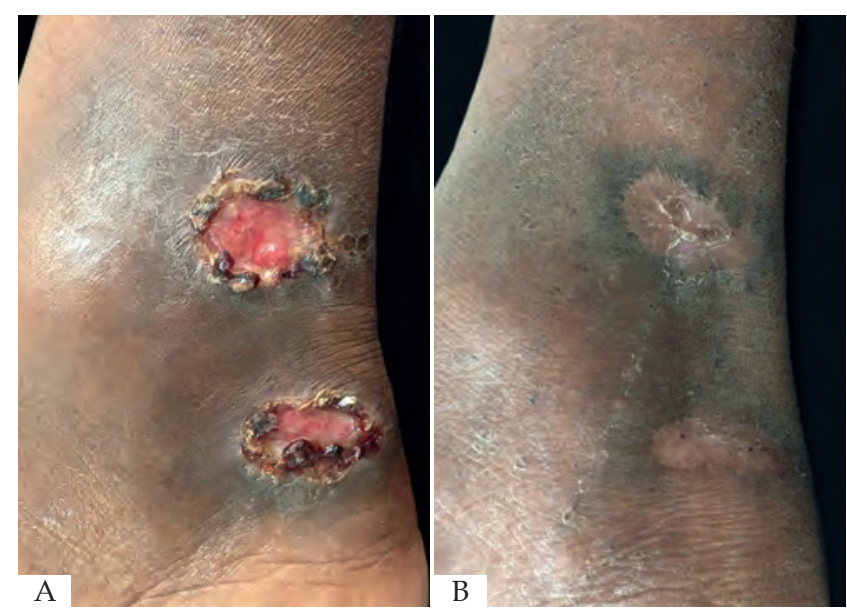

FiguRE 1: A - Before treatment with thermotherapy. B - After treatment with thermotherapy (only the larger lesion was treated) 
two involving L. tropica, we can see that the lesions caused by this species in the Old World respond more effectively to therapy with local heat, with a mean efficacy of $98 \%$ and $82.5 \%$, respectively. ${ }^{40,46}$

Most studies demonstrated that one single application of local heat by the radiofrequency device is enough to promote a complete reepithelialization of the lesions and achieve cure. Only in two studies thermotherapy was performed in more than one session. In one of them, performed in Guatemala, the regimen was of three weekly applications of thermotherapy with a cure rate of $73 \%$, and
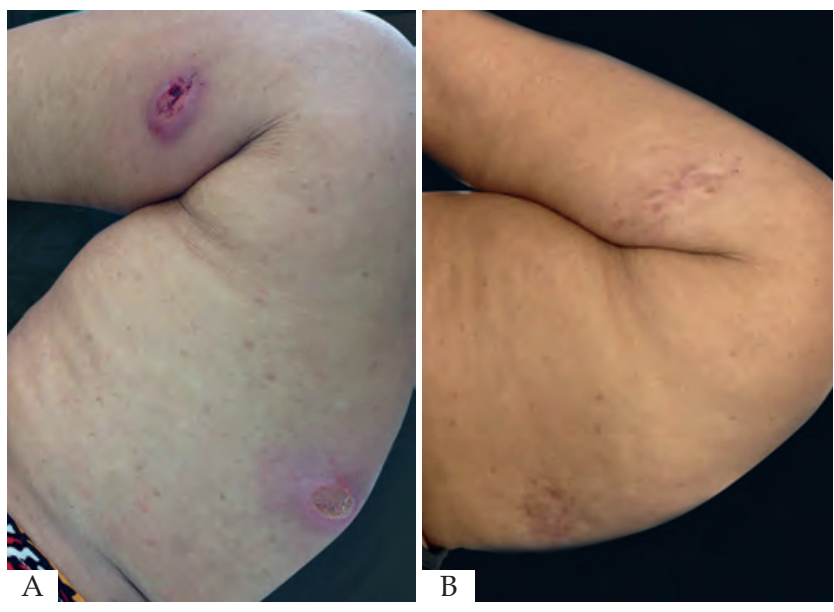

Figure 2: A - Before treatment with thermotherapy. B - After treatment with thermotherapy (the lesions healed only after two sessions in each ulcer)

TABLE 4: Cure rate per patient and lesion after treatment with thermotherapy

\begin{tabular}{llll}
$\begin{array}{l}\text { Treatment } \\
\text { evaluation }\end{array}$ & Total & Cure (\%) & CI 95\% \\
\hline Per patient & 15 & $13(86.7 \%)$ & $54.6 \%$ to $97.2 \%$ \\
Per lesion* & 21 & $18(85.7 \%)$ & $63.7 \%$ to $97.0 \%$ \\
\hline
\end{tabular}

CI $(95 \%)=95 \%$ confidence interval for the mean.

*Two lesions progressed to cure with no need for treatment and were not included in the table.
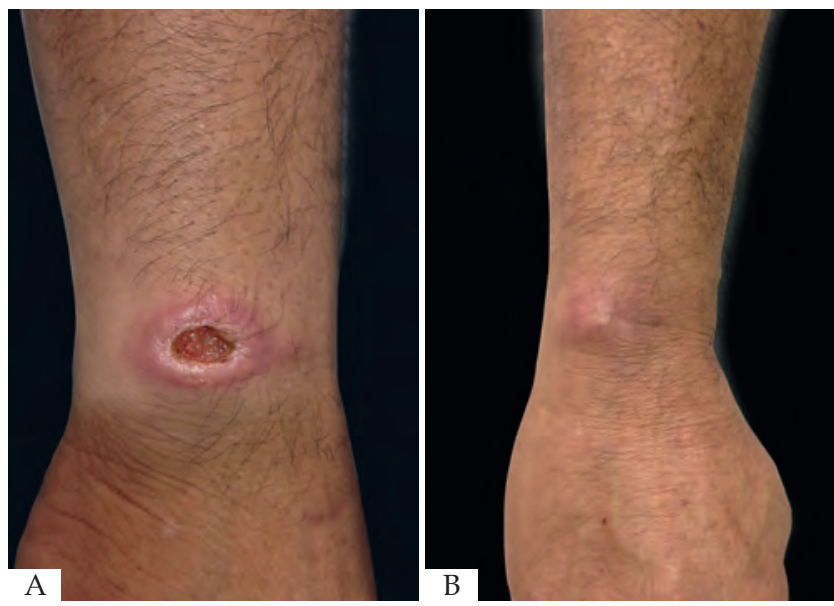

FiguRE 3: A - Before treatment with thermotherapy. B - After treatment with thermotherapy in the other performed in Iran, the authors opted to use the therapy once a week for four weeks, with an efficacy of $81 \%{ }^{34,38} \mathrm{~A}$ higher thermal dose with more applications or a higher temperature might improve the cure rates without increasing the side effects. However, in our study, we opted for the application of a single session of the therapy with good results.

The only study performed in Brazil with this device had the objective to determine if the healing of the CL lesions caused by therapy with local heat was associated to the modulation of the systemic response by inflammatory cytokines compared to conventional therapy with meglumine antimoniate. ${ }^{42}$ The evaluation of efficacy was impaired in this study since the patients who did not respond received the recommended treatment with pentavalent antimonial 28 days after the application of local heat. Thus, our study is groundbreaking in Brazil in regards to the evaluation of the efficacy of this alternative therapy to CL.

There is a lack of controlled studies with patients with multiple CL lesions. The aim would be to evaluate if it is necessary to treat all the lesions or if treatment of only the larger lesion with would be sufficient to induce an inflammatory response capable of promoting cure of the remaining lesions. In our study, of the seven patients with more than one lesions, only two showed healing of the untreated lesions. Five needed additional treatments for the smaller lesions, since after 30 days of follow-up they did not show any signs of reepithelialization. Of the eight lesions initially untreated, only two (25\%) progressed to healing without the need of local application. This systemic effect on the untreated lesions, confirmed by this study was described in a previous report. ${ }^{30}$ The mechanism for this distance cure effect is not known. Possibly, the inflammatory response generated on the site where the heat was applied induces a systemic immune response with an effect inducing distant healing.

The patients that did not progress with proper healing three months after the treatment were considered a therapeutic failure. They had a lesion area of $1,225 \mathrm{~mm}^{2}$ and $950 \mathrm{~mm}^{2}$. Most patients in the study had small lesions, with a mean lesion area of $410.17 \mathrm{~mm}^{2}$, being the smaller area $50 \mathrm{~mm}^{2}$ and the larger $1,400 \mathrm{~mm}^{2}$. It is possible that radiofrequency thermotherapy is not adequate to treat large lesions. Regardless of the treatment method, the larger the lesion, the lower the chances of cure. ${ }^{46}$ Besides, factors related to the host immune response and their nutritional status, as well as the virulence of the species involved in the disease could influence the patients' evolution to cure. ${ }^{47}$ One of these patients had a therapeutic failure and refused to treat with systemic pentavalent antimonial. Three months after a new thermotherapy treatment, there was complete healing of the ulcers and progression to cure.

After radiofrequency thermotherapy treatment all patients were instructed to use fusidic acid cream twice daily for seven days, what probably contributed to avoid secondary infection as a complication of the treatment. Studies in which such measure was not adopted report secondary infection rates of $7 \%$ and $19 \% .^{39,41}$ The main side effects seen were burning sensation, pain and itch. Only one patient had a more severe reaction with blisters on the treatment site. Despite this, the patient progressed well, with cure of their ulcer and optimal healing, with mild local erythema. 
All patients who responded to the treatment had an acceptable cosmetic result after 12 months of follow-up. Radiofrequency can induce collagen contraction, synthesis and remodeling. ${ }^{48}$ This way, most lesions treated acquired a color very similar to the original skin color of the patient, and the lesions that presented with depigmentation will probably improve their appearance over time, with a tendency to lightening of the hyperpigmented lesions and return of the pigmentation in hypopigmenteed lesions.

The heat produced by radiofrequency generates a local thermal dose. Thus, such as in all local therapies, it might not be able to cure distant lesions nor latent infections. This is a concern mainly in Central and South America, where CL by L. braziliensis is prevalent and the risk of the spreading of the infection to the mucous membranes continues to be worrisome. Besides, there is also the risk of indicating a local treatment for a disease that is not necessarily localized and that might have lymph node and mucosal involvement. Another disadvantage regarding thermotherapy is related to the duration of response and chances of recurrence. However, this possibility can also be extrapolated to systemic treatments that do not have enough confirmation of their efficacy in inhibiting the persistence or reactivation of parasites. In Guatemala, in more than 600 patients already treated with thermotherapy, there was no evidence of mucosal leishmaniasis after 12 months of follow-up. ${ }^{34}$ Moreover, in India, a long-term efficacy study did not show parasites in the skin through PCR even after 18 months of follow-up..$^{40}$

Along the years, the therapy with pentavalent antimonial has been used as the drug of choice for the treatment of CL. However, due to its toxicity, need for laboratory tests for monitoring, difficult administration, long time for treatment, poor adherence, cost and reduced efficacy over time attributable to incomplete administration of therapeutic regimens, their use should be restricted to those situations where systemic treatment is strictly necessary. Among these situations are cases of disseminated mucosal leishmaniasis, diffuse leishmaniasis and sites where heat therapy should be avoided, such as areas close to mucous membranes. Thus, most patients with few lesions of localized CL would be spared from a treatment more aggressive than the disease itself. This benefit would be especially important for elderly patients. Many times, this group of patients receive a toxic systemic treatment because of an ulcerated lesion that was not even confirmed to be CL with the parasitological methods. This would avoid fatal outcomes such as the ones previously reported. ${ }^{17,18}$
One of the main ways found to lessen the disadvantages of the use of systemic pentavalent antimonial is using it intralesionally. With this, most of the side effects are minimized. The efficacy of intralesional antimonial was already registered and it ranges from $80-92 \%{ }^{40,49}$ However, studies published in Iran show a not so high cure rate for this treatment modality, with an efficacy between 40 $60 \%{ }^{38,50}$ Other disadvantages include the need for multiple applications, reducing patient adherence, a larger amount of side effects when compared to thermotherapy, the cost and the need for laboratory monitoring.

New therapeutic options have been sought. However, despite good results, none of them was considered convenient or sufficiently effective to replace conventional treatment. Among the localized treatment options, radiofrequency thermotherapy appears as a viable option, since it is effective and requires only one session, improving patient adherence. One of the main advantages of this therapy is that the device is easy to use, light and works with rechargeable batteries, making it possible to be used in rural areas or areas with no electricity. Another advantage of this treatment modality is that it does not require monitoring with laboratory tests, saving additional costs for health institutions. Although the thermotherapy device is still relatively expensive, making it of difficult access in endemic countries, the costs related to conventional treatment are higher. Another possibility to be investigated is the association of thermotherapy to new oral treatment options, such as miltefosine, for example. All these advantages make this therapy a good alternative for the treatment of localized CL, particularly in patients who have absolute or relative contraindications to the conventional therapy, such as heart, kidney and liver conditions, pregnant women and HIV-positive patients.

\section{CONCLUSIONS}

Taking the results of this study into consideration, we conclude that radiofrequency thermotherapy can be considered as a possible alternative to pentavalent antimonials for the treatment of localized CL in Brazil, especially in cases of a single lesion and when there is formal contraindication to conventional treatment.

Additional randomized controlled studies are needed and are being conducted with a larger number of patients and a longer follow-up period, so that this treatment modality be considered as one of the main alternatives to conventional treatment for localized CL in Brazil. $\square$ 


\section{REFERENCES}

1. Alvar J, Vélez ID, Bern C, Herrero M, Desjeux P, Cano J, et al. Leishmaniasis Worldwide and Global Estimates of its Incidence. PLoS One. 2012;7:e35671.

2. World Health Organization (WHO). Control of the leishmaniasis: report of a meeting of the WHO Expert Committee on the Control of Leishmaniases, Geneva, 22-26 March 2010. Geneva: World Health Organization; 2010.

3. Brasil. Secretaria de Vigilância em Saúde. Manual de Vigilância da Leishmaniose Tegumentar Americana. 2 ed. rev. atual. Brasília: Ministério da Saúde; 2010.

4. Saude.gov.br [Internet]. Sistema Nacional de Vigilância em Saúde: Relatório de Situação. Piaui. [acesso 27 jun 2016]. Disponível em: http://portal.saude.gov.br/ svs/leishmaniosetegumentaramericana.

5. Mashayekhi-Ghoyonlo V, Kiafar B, Rohani M, Esmaeili H, Erfanian-Taghvaee MR. Correlation between Socioeconomic Status and Clinical Course in Patients with Cutaneous Leishmaniasis. J Cutan Med Surg. 2015;19:40-4.

6. Grimaldi G Jr, David JR, McMahon-Pratt D. Identification and distribution of New World Leishmania species characterized by serodeme analysis using monoclonal antibodies. Am J Trop Med Hyg. 1987:36:270-87.

7. Lainson R, Shaw JJ, Silveira FT, de Souza AA, Braga RR, Ishikawa EA. The dermal leishmaniases of Brazil, with special reference to the eco-epidemiology of the disease in Amazonia. Mem Inst Oswaldo Cruz. 1994;89:435-43.

8. Silveira FT, Lainson R, Corbett CE. Clinical and Immunopathological Spectrum of American Cutaneous Leishmaniasis with Special Reference to the Disease in Amazonian Brazil - A Review. Mem Inst Oswaldo Cruz. 2004;99:239-51.

9. David CV, Craft N. Cutaneous and mucocutaneous leishmaniasis. Dermatol Ther. 2009;22:491-502.

10. Bailey MS, Lockwood DN. Cutaneous leishmaniasis. Clin Dermatol. 2007;25:203-11.

11. Goto $\mathrm{H}$, Lindoso JA. Current diagnosis and treatment of cutaneous and mucocutaneous leishmaniasis. Expert Rev Anti Infect Ther. 2010;8:419-33.

12. Skraba CM, de Mello TF, Pedroso RB, Ferreira ÉC, Demarchi IG, Aristides SM, et al. Evaluation of the reference value for the Montenegro skin test. Rev Soc Bras Med.Trop. 2015;48: 437-44.

13. Costa JML, Vale KC , França F, Saldanha ACR, Silva JO, Lago EL, et al. Cura espontânea da leishmaniose causada por leishmania viannia braziliensis em lesões cutâneas. Rev Soc Bras Med Trop. 1990;23:205-8.

14. Almeida OL, Santos JB. Advances in the treatment of cutaneous leishmaniasis in the new world in the last ten years: a systematic literature review. An Bras Dermatol. 2011;86:497-506.

15. Hepburn NC, Nolan J, Fenn L, Herd RM, Neilson JM, Sutherland GR et al. Cardiac effects of sodium stibogluconate: myocardial, electrophysiological and biochemical studies. QJM. 1994:87:465-72.

16. Tuon FF, Amato VS, Graf ME, Siqueira AM, Nicodemo AC, Amato Neto V. Treatment of New World cutaneous leishmaniasis - a systematic review with a meta-analysis. Int J Dermatol. 2008:47:109-24.

17. Lima MVN de, Oliveira RZ de, Lima AP de, Cerino DA, Silveira TGV. American cutaneous leishmaniasis with fatal outcome during pentavalent antimoniate treatment. An Bras Dermatol. 2007;82:269-71.

18. Diniz DS, Costa AS, Escalda PM. The effect of age on the frequency of adverse reactions caused by antimony in the treatment of American tegumentary leishmaniasis in Governador Valadares, State of Minas Gerais, Brazil. Rev Soc Bras Med Trop. 2012;45: 597-600.

19. Name RQ, Borges KT, Nogueira LSC, Sampaio JHD, Tauil PL, Sampaio RNR. Clinical, epidemiological and therapeuthic study of 402 patients with American cutaneous leishmaniasis seen at University Hospital of Brasilia, DF, Brazil. An Bras Dermatol. 2005;80:249-54

20. Hadighi R, Boucher P, Khamesipour A, Meamar AR, Roy G, Ouellette M, et al. Glucantime-resistant Leishmania tropica isolated from Iranian patients with cutaneous leishmaniasis are sensitive to alternative antileishmania drugs. Parasitol Res. 2007;101: 1319-22.

21. Ourives-Neves L, Chrusciak-Talhari A, Gadelha EPN, da Silva Júnior RM, Guerra $J A O$, Ferreira $L C L$, et al. A randomized clinical trial comparing meglumine antimoniate, pentamidine and amphotericin B for the treatment of cutaneous leishmaniasis by Leishmania guyanensis. An Bras Dermatol. 2011;86: 1092-101.

22. de Paula CD, Sampaio JH, Cardoso DR, Sampaio RN. Estudo comparativo da eficácia de isotionato de pentamidina administrada em três doses durante uma semana e de $\mathrm{N}$-metilglucamina $20 \mathrm{mgSbV} / \mathrm{kg} /$ dia durante 20 dias para 0 tratamento da forma cutânea da leishmaniose tegumentar americana. Rev Soc Bras Med Trop. 2003;36:365-71.
23. Netto EM, Tada MS, Golightly L, KalterDC, Lago E, Barreto AC, et al. Conceito de uma população local a respeito da leishmaniose mucocutânea em uma área endêmica. Rev Soc Bras Med Trop. 1985;18: 33-7.

24. Moreira RCR, Rebêlo JMM, Gama MEA, Costa JML. Nivel de conhecimentos sobre Leishmaniose Tegumentar Americana (LTA) e uso de terapias alternativas por populações de uma área endêmica da Amazônia do Maranhão, Brasil. Cad Saúde Pública. 2002;18: 187-95.

25. Follador I, Araujo C, Cardoso MA, Tavares-Neto J, Barral A, Miranda JC, et al. Surto de leishmaniose tegumentar americana em Canoa, Santo Amaro, Bahia, Brasil. Rev Soc Bras Med Trop. 1999;32:497-503.

26. Weigel MM, Armijos RX. The traditional and conventional medical treatment of cutaneous leishmaniasis in rural Ecuador. Rev Panam Salud Publica. 2001;10:395-404

27. Berman JD, Neva FA. Effect of temperature on multiplication of Leishmania amastigotes within human monocyte-derived macrophages in vitro. Am J Trop Med Hyg. 1981;30:318-21.

28. Sacks DL, Barral A, Neva FA. Thermosensitivity patterns of Old vs. New World cutaneous strains of Leishmania growing within mouse peritoneal macrophages in vitro. Am J Trop Med Hyg. 1983;32:300-4.

29. Neva FA, Petersen EA, Corsey R, Bogaert H, Martinez D. Observations on local heat treatment for cutaneous leishmaniasis. Am J Trop Med Hyg. 1984;33:800-4.

30. Junaid AJ. Treatment of cutaneous leishmaniasis with infrared heat. Int $J$ Dermatol. 1986;25:470-2.

31. Sharquie KE, al-Hamamy H, el-Yassin D. Treatment of cutaneous leishmaniasis by direct current electrotherapy: the Baghdadin device. J Dermatol. 1998;25:234-7.

32. Shamsi Meymandi S, Zandi S, Aghaie H, Heshmatkhah A. Efficacy of $\mathrm{CO}(2)$ laser for treatment of anthroponotic cutaneous leishmaniasis, compared with combination of cryotherapy and intralesional meglumine antimoniate. J Eur Acad Dermatol Venereol. 2011;25:587-91.

33. Barbosa AF, Sangiorgi BB, Galdino SL, Barral-Netto M, Pitta IR, Pinheiro AL. Photodynamic antimicrobial chemotherapy (PACT) using phenothiazine derivatives as photosensitizers against Leishmania braziliensis. Lasers Surg Med. 2012;44:850-5.

34. Navin TR, Arana BA, Arana FE, de Mérida AM, Castillo AL, Pozuelos JL. Placebocontrolled clinical trial of meglumine antimonate (glucantime) vs. localized controlled heat in the treatment of cutaneous leishmaniasis in Guatemala. Am J Trop Med Hyg. 1990;42:43-50.

35. Vega JC, Sanchez BF, Montero LM, Montaña R, Mahecha Mdel P, Dueñes B, et al. The efficacy of thermotherapy to treat cutaneous leishmaniasis in Colombia: a comparative observational study in an operational setting. Trans R Soc Trop Med Hyg. 2009;103:703-6.

36. López L, Robayo M, Vargas M, Vélez ID. Thermotherapy. An alternative for the treatment of American cutaneous leishmaniasis. Trials. 2012;13:58.

37. Reithinger R, Mohsen M, Wahid M, Bismullah M, Quinnell RJ, Davies CR, et al. Efficacy of thermotherapy to treat cutaneous leishmaniasis caused by Leishmania tropica in Kabul, Afghanistan: a randomized, controlled trial. Clin Infect Dis. 2005:40:1148-55.

38. Sadeghian G, Nilfroushzadeh MA, Iraji F. Efficacy of local heat therapy by radiofrequency in the treatment of cutaneous leishmaniasis, compared with intralesional injection of meglumine antimoniate. Clin Exp Dermatol. 2007;32:371-4.

39. Aronson NE, Wortmann GW, Byrne WR, Howard RS, Bernstein WB, Marovich MA, et al. A randomized controlled trial of local heat therapy versus intravenous sodium stibogluconate for the treatment of cutaneous Leishmania major infection. PLoS Negl Trop Dis. 2010;4:e628.

40. Bumb RA, Prasad N, Khandelwal K, Aara N, Mehta RD, Ghiya BC, et al. Longterm efficacy of single-dose radiofrequency-induced heat therapy vs. intralesional antimonials for cutaneous leishmaniasis in India. $\mathrm{Br} \mathrm{J}$ Dermatol. 2013 May; $168: 1114-9$.

41. López L, Cruz C, Godoy G, Robledo SM, Vélez ID. Thermotherapy effective and safer than miltefosine in the treatment of cutaneous leishmaniasis in Colombia. Rev Inst Med Trop Sao Paulo. 2013;55: 197-204.

42. Lobo IM, Soares MB, Correia TM, de Freitas LA, Oliveira MI, Nakatani M, et al. Heat therapy for cutaneous leishmaniasis elicits a systemic cytokine response similar to that of antimonial (Glucantime) therapy. Trans R Soc Trop Med Hyg. 2006;100:642-9.

43. Lakhal-Naouar I, Slike BM, Aronson NE, Marovich MA. The Immunology of a Healing Response in Cutaneous Leishmaniasis Treated with Localized Heat or Systemic Antimonial Therapy. PLoS Negl Trop Dis. 2015 ;9: e0004178. 
44. Prasad N, Ghiya BC, Bumb RA, Kaushal H, Saboskar AA, Lezama-Davila CM, et al. Heat, Oriental sore, and HIV. Lancet. 2011;377:610.

45. Cardona-Arias JA, Vélez ID, López-Carvajal L. Efficacy of thermotherapy to treat cutaneous leishmaniasis: A meta-analysis of controlled clinical trials. PLoS One. 2015:10:1-15.

46. Safi N, Davis GD, Nadir M, Hamid H, Robert LL Jr, Case AJ. Evaluation of thermotherapy for the treatment of cutaneous leishmaniasis in Kabul, Afghanistan: a randomized controlled trial. Mil Med. 2012;177:345-51.

47. Hepburn N. Cutaneous leishmaniasis: an overview. J Postgrad Med. 2003;49:50-4.
48. Alster TS, Tanzi E. Improvement of Neck and Cheek Laxity with a Nonablative Radiofrequency Device: A Lifting Experience. Dermatol Surg. 2004;30: 503-7

49. Oliveira-Neto MP, Schubach A, Mattos M, da Costa SC, Pirmez C. Intralesional therapy of American cutaneous leishmaniasis with pentavalent antimony in Rio de Janeiro, Brazil-an area of Leishmania (V.) braziliensis transmission. Int J Dermatol. 1997;36:463-8.

50. Asilian A, Sadeghinia A, Faghihi G, Momeni A. Comparative study of the efficacy of combined cryotherapy and intralesional meglumine antimoniate (GlucantimeR) vs. cryotherapy and intralesional meglumine antimoniate (GlucantimeR) alone for the treatment of cutaneous leishmaniasis. Int J Dermatol. 2004;43:281-3.
Sheila Viana Castelo Branco Gonçalves

Carlos Henrique Nery Costa
iD ORCID 0000-0002-3405-0386

iD ORCID 0000-0001-7302-2006

How to cite this article: Gonçalves SVCB, Costa CHN. Treatment of cutaneous leishmaniasis with thermotherapy in Brazil: an efficacy and safety study. An Bras Dermatol. 2018;93(3):347-55. 